\title{
Effects of porcine granulocyte-macrophage-colony-stimulating factor on porcine cumulus-oocyte complex maturation in vitro
}

\author{
Long Thanh Dang ${ }^{1,2, *}$, Thu-Thao Thi Le ${ }^{2}$, Cam Manh Huynh ${ }^{2}$, Son Nghia Hoang ${ }^{3}$
}

${ }^{1}$ Stem Cell Institute, University of Science, Vietnam National University Ho Chi Minh City, Vietnam

${ }^{2}$ Laboratory of Stem Cell Research and Application, University of Science, Vietnam National University - Ho Chi Minh City, Vietnam

${ }^{3}$ Institute of Tropical Biology, Vietnam Academy of Science and Technology, Vietnam

\section{Correspondence}

Long Thanh Dang, Stem Cell Institute, University of Science, Vietnam Nationa University - Ho Chi Minh City, Vietnam

Laboratory of Stem Cell Research and Application, University of Science,

Vietnam National University - Ho Chi

Minh City, Vietnam

Email: dtlong@hcmus.edu.vn

History

- Received: Sept 102017

- Accepted: Dec 122017

- Published: Jan 212019

DOI : 10.15419/bmrat.v6i1.514

\section{Check for updates}

\section{Copyright}

(c) Biomedpress. This is an openaccess article distributed under the terms of the Creative Commons Attribution 4.0 International license.

\begin{abstract}
Introduction: The in vitro maturation (IVM) of oocytes is an essential step in the in vitro embryo production. This study aimed to improve the efficacy of IVM by supplementing with granulocytemacrophage colony stimulating factor (GM-CSF) in the culture medium. Methods: The combinatorial effects of GM-CSF and porcine follicular fluid (pFF) were also investigated in porcine cumulusoocyte complex (COC) models. COCs were obtained by aspirating follicles with an $18 \mathrm{G}$ needles. Small and medium follicles were used in this study. COCs from two kinds of follicles were divided into 13 groups to investigate the maturation of COCs at different concentrations of pFF $(0,10 \%)$ and $\operatorname{GM}-\operatorname{CSF}(0,2,10,20 \mathrm{ng} / \mathrm{mL})$. The maturation of COCs was evaluated by different variables including cumulus expansion, the appearance of the first polar body, lipid droplet localization, mitochondrial distribution, and cortical granule distribution. Results: The results showed that GM-CSF improves the cumulus expansion, and stimulate the mitochondrial and cortical granule movement. However, GM-CSF did not increase nuclear maturation or lipid droplet localization rates in the porcine oocyte. Conclusion: In conclusion, porcine GM-CSF had some positive effects on the porcine oocyte maturation.

Key words: Cortical granule distribution, Cumulus expansion, Lipid droplet localization, Mitochondrial distribution
\end{abstract}

\section{INTRODUCTION}

In vitro maturation (IVM) is an assisted reproductive technology for women. It is usually indicated for cases with problems in oocyte maturation such as Polycystic Ovary Syndrome (PCOS). The advantages of IVM include low cost, short time, and especially limiting harmfulness to patients by using just small doses of steroid hormones. Thus, IVM can be used as an alternative for superovulation technique in the conventional in vitro fertilization procedures. However, the quality of oocytes after IVM is variable, leading to low rates of embryonic development when compared to that of oocytes matured in vivo ${ }^{1}$.

Oocyte maturation is enhanced by the addition of follicular fluid (FF) to media by increasing the rate of successful maturation, monospermic fertilization, and promote male pronucleus formation ${ }^{2}$. The effects of FF can be further enhanced by the combination of growth factors, amino acids, hormones, cytokines, etc. $^{3-5}$. However, the composition of FF is complex, and the roles and concentration of many substances in FF are unknown. Although FF is commonly added to porcine IVM medium, its quality varies from ovary to ovary and depends on the size of the follicles.

Granulocyte-macrophage colony-stimulating factor (GM-CSF) is known as colony-stimulating factor
2 in the CSF family. When it was first discovered in the 1960s, colony-stimulating factor (CSF) was the general name for cytokines responsible for promoting the proliferation of bone marrow cells in culture. By the early 1970s, the scientists had established that there were four CSFs: Granulocyte colony-stimulating factor (G-CSF), Macrophage colony-stimulating factor (M-CSF), Granulocytemacrophage colony-stimulating factor (GM-CSF), and multi-CSF. GM-CSF was the first of the CSFs to be described chemically.

GM-CSF is a glycoprotein with structure and molecular weight different from species to species. In myeloid cells, GM-CSF binds to a specific receptor on the cell membrane with a high affinity. The receptor is composed of two subunits, $\alpha$ and $\beta$ : the $\alpha$-subunit is unique to GM-CSF but has low affinity; the $\beta$-subunit is shared by the interleukin (IL)- 5 and interleukin3 (IL-3) receptors ${ }^{6}$. When combining into the receptor complex, they convert the low-affinity interaction to a high affinity interaction ${ }^{7,8}$. By binding to its receptor, GM-CSF induces changes in gene expression through the Janus kinase/signal transducers and activators of transcription (JAK/STAT), Ras/Raf/mitogen-activated protein kinase, mitogenactivated protein kinase (MAPK), and phosphatidyli- 
nositol 3-kinase (PI3-K) pathways ${ }^{6}$.

In 1977, GM-CSF was purified from mouse lung for the first time ${ }^{9}$. At first, GM-CSF was believed to only stimulate the generation of both macrophage and granulocyte colonies from hematopoietic precursor cells ${ }^{10}$. However, with new evidence, GM-CSF is known to have effects on various cell types and organs such as liver ${ }^{11}$, kidney ${ }^{12}$, brain ${ }^{13}$ etc. After almost forty years, the biological aspect of GM-CSF has been well-studied. GM-CSF can be produced by many cell types such as activated T-cell, B-lymphocytes, endothelial cells, keratinocytes, fibroblasts, and evenly tumor cells ${ }^{14,15}$. GM-CSF synthesis is regulated by a variety of factors such as prostaglandin, toll-like receptor (TLR) agonists, TNF- $\alpha$, interleukin-1, T-cell receptor, and co-receptor stimulation ${ }^{16-18}$. In addition to being found in hematopoietic cells, the GMCSF receptor is also present on the membrane of microglia, endothelial cells, mesenchymal cells, and tumor-derived cells ${ }^{19}$. Studies have shown that the regulatory functions of GM-CSF are important in cell proliferation, cell differentiation, cell activation, apoptosis inhibition ${ }^{20}$, and maybe more.

While studying female gonad, GM-CSF and its receptor were found in uterus, oviducts, ovaries, and follicles $^{8}$. The presence of GM-CSF in these organs suggested the importance of GM-CSF in the reproduction. In a study investigating the physiological role of GM-CSF in ovaries, mice that lost the GM-CSF gene had a longer estrous cycle by 1.5 days, a lower number of cells in the ovaries, and a slow progesterone synthesis during pregnancy ${ }^{21}$. In addition, progesterone and estrogen concentration control the GM-CSF synthesis, which suggests that GM-CSF may have a regulating function during estrous cycles in mammals. Thus, the expression of GM-CSF in the ovary and uterus, coupled with its regulatory function as a steroid, further indicates the functions of GM-CSF in the normal physiology of the reproductive system.

In the follicles, the expression level of GM-CSF receptor in theca, granulosa, and luteal cells coincides with the stage of follicular development, ovulation, and luteal phase formation. The murine cumulus-oocyte complexes (COCs) express mRNA for the $\alpha$-subunit of the GM-CSF receptor, which facilitates the uptake of glucose, and enhances the viability of oocytes ${ }^{8,22}$. GM-CSF receptor is also present on the membrane of immature oocytes, fertilized oocytes, and embryo at the blastocyst stage in both humans and mice ${ }^{23}$. In addition, the previous studies showed that GM-CSF was found in the FF with a lower concentration than in the serum ${ }^{24,25}$. As such, GM-CSF may have important roles in the development and maturation of oocytes.
In this study, we investigated the effects of GM-CSF individually as well as combinedly with the porcine follicular fluid (pFF) on the IVM of the cumulusoocyte complex.

\section{METHODS}

\section{Porcine ovary collection}

At local slaughterhouses, the porcine ovaries were collected immediately when the female gonads were exposed. Pink ovaries with even follicles containing clear fluid were chosen. Then, the ovaries were washed with warm saline solution supplemented with $100 \mathrm{IU} / \mathrm{mL}$ penicillin and $0.1 \mathrm{mg} / \mathrm{mL}$ streptomycin sulfate to remove blood and contaminants. The ovaries were stored in the saline solution with antibiotic supplements at $32-38 \mathrm{oC}$ and transfer to the laboratory within one hour.

\section{Porcine follicular fluid preparation}

The porcine follicular fluid ( $\mathrm{pFF}$ ) was prepared as the published study ${ }^{2}$. Briefly, pFF was extracted from 3 to $7 \mathrm{~mm}$ follicles of porcine ovaries. After centrifugation for $30 \mathrm{~min}$ at $13,000 \mathrm{rpm}$ at $4^{\circ} \mathrm{C}$, the supernatants were collected and filtered through $0.45 \mathrm{~mm}$ filters (Gelman Sciences, Ann Arbor, MI). The pFF was stored at $-20^{\circ} \mathrm{C}$ immediately until used ${ }^{2}$.

\section{Cumulus-0ocyte complex (COCs) collection}

COCs were collected by aspirating small follicles (SF) (1-3 mm) and medium follicles (MF) (3-7 mm). The COCs were aspirated using an $18-\mathrm{G}$ needle attached to a $10 \mathrm{ml}$ disposable syringe with modified $\mathrm{D}$ PBS (Dulbecco's PBS supplemented with 3.5\% bovine serum albumin, $1 \mathrm{~g} / \mathrm{L}$ D-glucose and $36 \mathrm{mg} / \mathrm{L}$ sodium pyruvate, $100 \mathrm{IU} / \mathrm{mL}$ penicillin and $0.1 \mathrm{mg} / \mathrm{mL}$ streptomycin sulfate).

\section{In vitro maturation}

Only compacted COCs with more than three uniform layers of cumulus cells and homogenous cytoplasm were rinsed twice with in vitro maturation medium (IVMM) and incubated at $38.5{ }^{\circ} \mathrm{C}$ in a humidified atmosphere of $5 \% \mathrm{CO}_{2}$. The IVMM was M199 (Gibco, Thermo Fisher Scientific, MA) supplemented with $0.1 \%$ polyvinyl alcohol (PVA), $0.57 \mathrm{mM}$ L-cysteine, $0.91 \mathrm{mM}$ sodium pyruvate, $3.05 \mathrm{mM} \mathrm{D}$ glucose, $10 \mathrm{ng} / \mathrm{mL}$ epidermal growth factor (EGF), 10 $\mathrm{IU} / \mathrm{mL}$ pregnant mare serum gonadotropin (PMSG), $10 \mathrm{IU} / \mathrm{mL}$ human chorionic gonadotropin (hCG), 50 $\mathrm{IU} / \mathrm{mL}$ penicillin and $50 \mathrm{mg} / \mathrm{mL}$ streptomycin sulfate $^{26}$. 
To evaluate the $\mathrm{pFF}$ and GM-CSF effects on the maturation of COCs, COCs were cultured in various conditions that IVMM supplemented with or without $10 \% \mathrm{pFF}$ in combination with different concentrations of GM-CSF. COCs were divided into two groups based on the diameter of follicles: small follicles and medium follicles. These COCs were divided into the following 13 groups with different culture medium and diameter of follicles with at least 30 COCs per sub-groups:

SF-G0: COCs from small follicles were cultured in IVMM without $\mathrm{pFF}$ or GM-CSF supplement SF-G2: COCs from small follicles were cultured in IVMM with $2 \mathrm{ng} / \mathrm{mL}$ GM-CSF, without $\mathrm{pFF}$ SF-G10: COCs from small follicles were cultured in IVMM with $10 \mathrm{ng} / \mathrm{mL}$ GM-CSF, without $\mathrm{pFF}$ SF-P0: COCs from small follicles were cultured in IVMM with $10 \% \mathrm{pFF}$, without GM-CSF

SF-P2: COCs from small follicles were cultured in IVMM with $10 \% \mathrm{pFF}$ and $2 \mathrm{ng} / \mathrm{mL}$ GM-CSF

SF-P10: COCs from small follicles were cultured in IVMM with $10 \% \mathrm{pFF}$ and $10 \mathrm{ng} / \mathrm{mL}$ GM-CSF

MF-G0: COCs from medium follicles were cultured in IVMM without $\mathrm{pFF}$ or GM-CSF supplement

MF-G2: COCs from medium follicles were cultured in IVMM with $2 \mathrm{ng} / \mathrm{mL}$ GM-CSF, without $\mathrm{pFF}$

MF-G10: COCs from medium follicles were cultured in IVMM with $10 \mathrm{ng} / \mathrm{mL}$ GM-CSF, without $\mathrm{pFF}$

MF-P0: COCs from medium follicles respectively were cultured in IVMM with $10 \%$ pFF, without GMCSF

MF-P2: COCs from medium follicles were cultured in IVMM with $10 \% \mathrm{pFF}$ and $2 \mathrm{ng} / \mathrm{mL}$ GM-CSF

MF-P10: COCs from medium follicles were cultured in IVMM with $10 \% \mathrm{pFF}$ and $10 \mathrm{ng} / \mathrm{mL}$ GM-CSF MF-P20: COCs from medium follicles were cultured in IVMM with $10 \% \mathrm{pFF}$ and $20 \mathrm{ng} / \mathrm{mL}$ GM-CSF

\section{Assessment of cumulus expansion}

At 0 and $20^{\text {th }}$ hour in IVM, COCs were microphotographed, and the diameter of each COC was measured with AxioVision Microscope Software (Carl Zeiss, Germany).

\section{Assessment of the first polar body}

After incubating for 40-44 hours, COC-culturing medium was added with hyaluronidase enzyme till achieving concentration at $80 \mathrm{IU} / \mathrm{mL}$ and aspirated for 1-2 minutes or until the oocytes were denuded almost completely. Then, the oocytes were quickly rinsed in pre-warmed IVMM two times to remove the enzyme. Finally, each group of 10-15 oocytes was allocated into 50-mL drops of pre-warmed IVMM overlaid with mineral oil. Each oocyte was rotated with microinjection pipette using a micromanipulation system (Eppendorf, Germany) to visualize the first polar body ${ }^{27}$.

To assess the agency of IVM, oocytes were classified based on the first polar body morphology according to the method of Lin T. et al. with some modifications ${ }^{28}$. "Class A" oocytes were defined as round or ovoid polar body with an intact membrane (smooth surface or not). Otherwise, "Class B" oocytes were defined with a broken or fragmented polar body, and were considered as poor quality (Figure 1).

\section{Assessment of lipid droplet localization}

The oocytes were evaluated by the method of $\mathrm{Hi}$ raga K. et al. (2013) with some modifications ${ }^{29}$. Briefly, with the micromanipulation system, the denuded oocytes were observed with an inverted microscope and classified into two groups according to the localization patterns of lipid droplets. "Class I" group included oocytes with the lipid droplets distributed centrally and had a light ring between membrane and lipid droplets. "Class II" group included oocytes with the lipid droplets located uniformly throughout the entire cytoplasm (Figure 2).

\section{Assessment of mitochondrial distribution}

After denuding, the oocytes were transferred into prewarmed IVMM supplemented with $0.5 \mathrm{mM}$ MitoTracker Red CMXRos (Invitrogen, USA) and incubated for 30 minutes at $38.5^{\circ} \mathrm{C}$ in $5 \% \mathrm{CO}_{2}$. Then, oocytes were rinsed twice in IVMM for 15 minutes each and fixed in 4\% paraformaldehyde in PBS for 30 $\min$ at $38.5^{\circ} \mathrm{C}$ in $5 \% \mathrm{CO}_{2}$. Finally, the oocytes were mounted between a glass slide and a coverslip. Scans and records were taken through the equatorial flat of the oocyte using a confocal laser scanning microscopy system (LSM 800, Carl Zeiss, Germany) with $39 \mu \mathrm{m}$ pinhole.

The mitochondrial distribution includes three patterns $^{30}$ :

- Type P: the peripheral pattern showed mitochondria distributed in proximity to oolema

- Type S: the semiperipheral pattern showed mitochondria covering the outer part of the cytoplasmic volume heterogeneously or/and in proximity to oolema

- Type M: the diffuse pattern showed mitochondria distributed homogeneously throughout the ooplasm. Oocytes with the diffuse pattern were classified as mature and those with peripheral and semiperipheral mitochondrial distributions were classified as immature (Figure 3). 


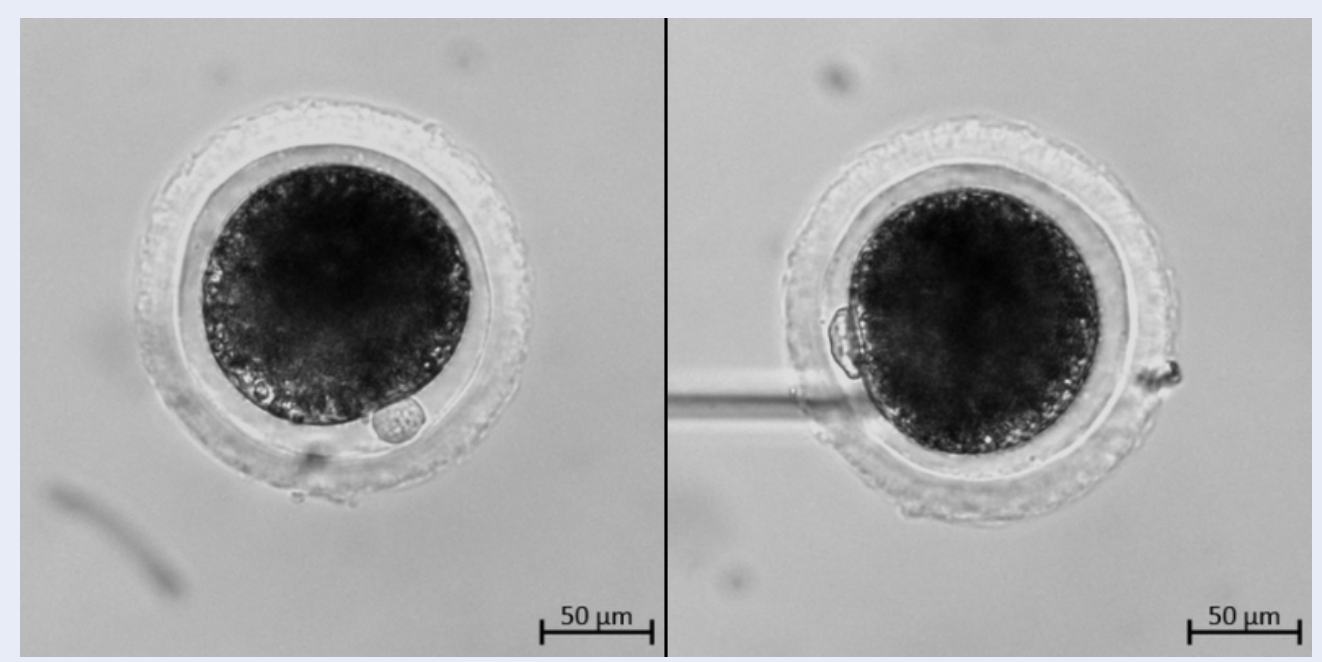

Figure 1: The porcine oocytes with first polar body after IVM. (Left) Class A oocyte with the round or ovoid polar body. (Right) Class B oocyte with broken or fragmented polar body

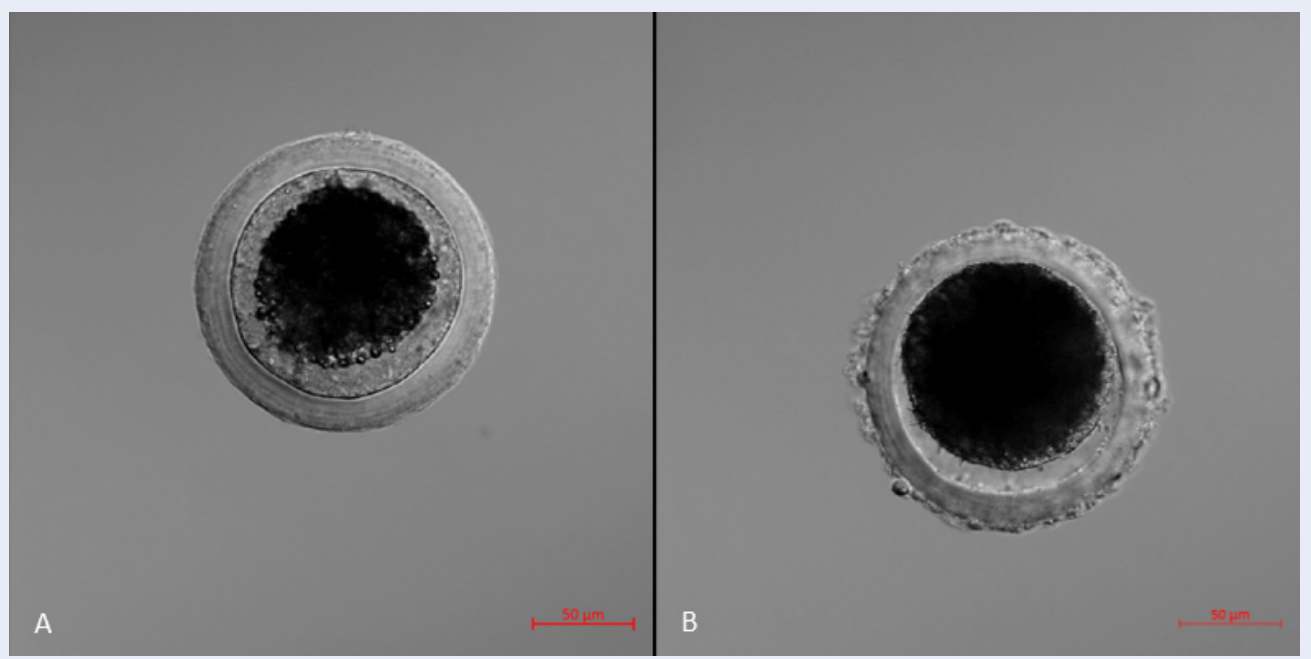

Figure 2: The localization patterns of lipid droplets in porcine oocytes after IVM. (A) Class I oocyte with the lipid droplets distributed centrally and a light ring outside. (B) Class II oocyte with the lipid droplets located uniformly throughout the entire cytoplasm.

\section{Assessment of the cortical granule distribu-} tion

The denuded oocytes were fixed with $4 \%$ paraformaldehyde in PBS for 30 minutes at room temperature. Then, oocytes were permeabilized with $0.1 \%$ Triton X-100 in PBS for 10 minutes and rinsed with blocking solution (PBS containing 0.3\% BSA and $100 \mathrm{mM}$ glycine) for 10 minutes. Next, the oocytes were stained with $10 \mathrm{mg} / \mathrm{mL}$ fluorescein isothiocyanate-labeled peanut agglutinin in PBS for 30 minutes in the dark at room temperature. After staining, the oocytes were rinsed twice in PBS for 10 minutes each. Finally, the oocytes were mounted on a slide, and then scanned and recorded as described previously $^{31}$.

The cortical granule distribution is divided into three patterns:

Type W: fluorescent signals were distributed in the whole oocyte cytoplasm

Type C: fluorescent signals covering the cortex and in proximity to oolema

Type M: the CGs were closely located beneath the 


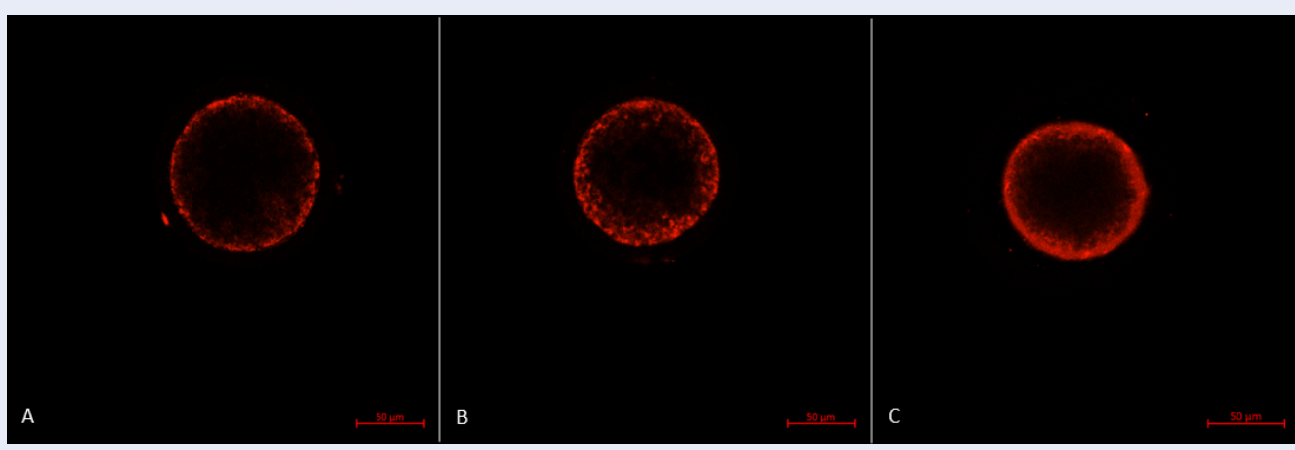

Figure 3: The mitochondrial distribution in porcine oocytes after IVM. (A) Type P oocyte with the peripheral pattern: mitochondria distributed near oolema. (B) Type S oocyte with the semiperipheral pattern: mitochondria distributed in the outer part of the cytoplasmic volume heterogeneously and near oolema. (C) Type M oocyte with the diffuse pattern: mitochondria distributed homogeneously throughout the ooplasm.

membrane and formed a brilliant continuous ring (Figure 4).

The oocytes with CG fluorescent signals beneath the membrane were classified as mature and those with the other types of cortical granule distribution as immature.

\section{Statistical analysis}

At least 30 COCs in each group were analyzed. The data was carried out using analysis of variance (ANOVA) for cumulus expansion assessment and Chi-square test for ratio comparisons. The P-value was calculated by using GraphPad Prism 6.0 software. Unless otherwise indicated, differences of $\mathrm{P}<0.05$ were considered significant.

\section{RESULTS}

\section{GM-CSF stimulated the cumulus expansion} during IVM of COCs from medium follicles

In this experiment, COCs from medium follicles were used to evaluate the effects of GM-CSF and pFF on IVM. The results represented in the Figure 5 showed that after 20 hours of culture in some different conditions (MF-G0, MF-G2, MF-G10, MF-P0, MF-P2, MF$\mathrm{P} 10$, MF-P20), the cumulus expansion was different between these groups.

Compared to before culturing, the COCs of MFG2, MF-G10, MF-P0, MF-P2, MF-P10 and MF-P20 significantly increased their cumulus layer $(\mathrm{p}<0.05)$. However, this observation was not observed in MFG0 (without supplements of pFF or GM-CSF).

The results also showed that the cumulus expansion of COCs in groups MF-G10 (only supplemented with GM-CSF) and MF-P0 (only supplemented with pFF) were similar ( $p>0.05)$, and significantly different from the group MF-G0 $(\mathrm{p}<0.01)(238.7 \pm 52.8,243.7 \pm$ 41.7 and $200.3 \pm 34.0$, respectively). While in the groups MF-P2, MF-P10, and MF-P20 that supplemented both pFF and GM-CSF (304.8 \pm 85.1, 301.6 \pm 89.6 and $307.2 \pm 98.3$, respectively), the cumulus expansion was stronger than in MF-P0 that only supplemented pFF (Figure 5).

GM-CSF did not improve the appearance and morphology of the first polar body of both oocytes from small follicles and medium follicles

The supplement of pFF in IVMM of SF-P0 and MF$\mathrm{P} 0$ group slightly increased the percentage of matured oocytes with the first polar body extrusion compared to SF-G0 and MF-G0 group (without supplements of pFF or GM-CSF), respectively, but this increase was non-significant.

In the MFs, when assessing only GM-CSF supplemented groups, the polar body extrusion rate in MFG10 group $(64.1 \%)$ was significantly lower $(\mathrm{P}<0.05)$ than in MF-G0 group (75\%). Similarly, the percentage of oocytes with the first polar body appeared in the pFF and GM-CSF supplemented groups reduced after cultured in IVMM. This rate in MF-P0 decreased significantly from $84 \%$ to $72,5 \%$ in MF-P10 ( $<<0.05)$ and $65,2 \%$ in MF-P20 group ( $\mathrm{P}<0.001)$.

However, the effects of $\mathrm{pFF}$ and GM-CSF on the appearance of the first polar body in oocytes from SFs were different to from MFs. The supplements of GM-CSF at $2 \mathrm{ng} / \mathrm{mL}$ (group SF-P2) and $10 \mathrm{ng} / \mathrm{mL}$ (group SF-P10) to pFF-supplemented IVMM slightly increased the percentage of oocytes appearing the first polar body. The oocytes' polar body extrusion in only GM-CSF-supplemented groups (SF-G2 and 


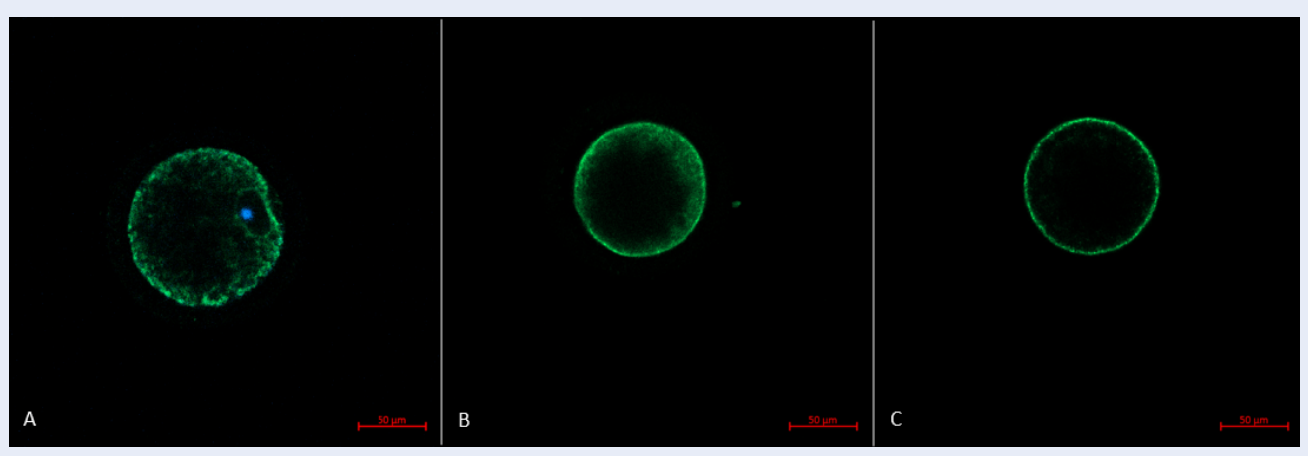

Figure 4: The cortical granule distribution in porcine oocytes after IVM. (A) Type W oocyte: The cortical granules distributed in the whole oocyte cytoplasm. (B) Type C oocyte: The cortical granules covered the cortex and in close to oolema; Type M oocyte: The cortical granules were closely located beneath the membrane and formed a brilliant continuous ring. Green: FITC- labeled peanut agglutinin. Blue: Hoechst 33342.

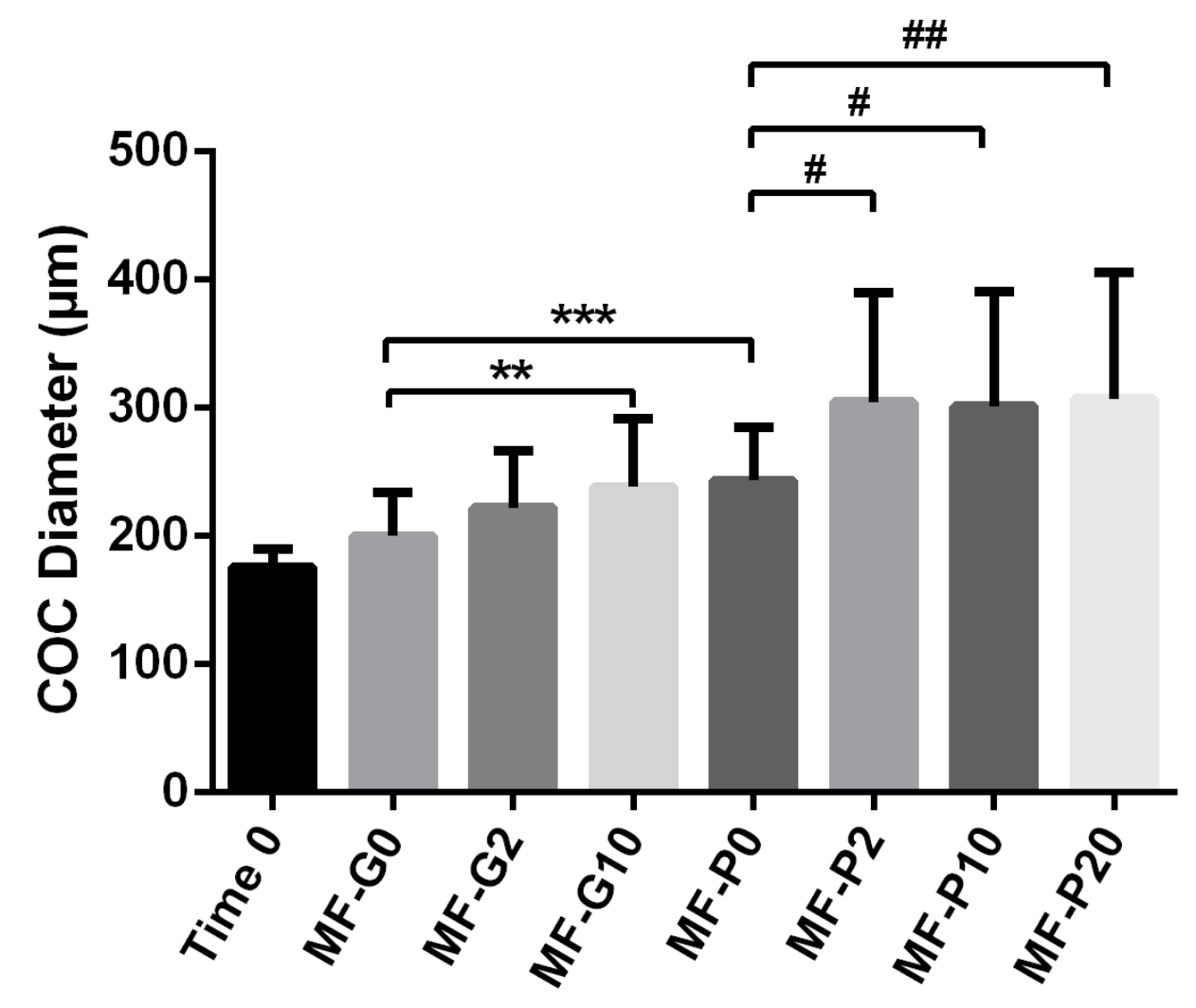

Figure 5: The diameters of COCs from medium follicles before and after 20 hours of IVM. Time 0 (before culture) revealed the average diameter of $\mathrm{COCs}$ in all groups at the culture starting time. The graph did not express a significant difference between the average diameter of $\mathrm{COCs}$ of individual groups (except for no supplemented GM-CSF group) and that at time $0(P<0.05)$. \# significant difference with $P<0.05$; \#\# and ${ }^{* *}$ significant difference with $\mathrm{P}<0.01 ;{ }^{* * *}$ significant difference with $\mathrm{P}<0.0001$ 
SF-G10) also slightly increased compared to without GM-CSF group (SF-G0). Although, these increases were not strong enough to be significant (Figure 6). Results of the first polar body morphological assessment showed that non-significant difference was detected in all groups of COCs from either MFs or SFs.

GM-CSF did not improve the lipid droplets distribution of both oocytes from SFs and MFs

The effects of pFF and GM-CSF on lipid droplet distribution of oocytes from small and medium follicles were presented in Figure 7. For the MFs, results showed that pFF significantly increased the rearrangement and distribution of lipid droplets inside the oocytes in MF-P0 compared to MF-G0 $(\mathrm{p}<0.05)$ ( $60.6 \%$ and $35.3 \%$, respectively). The supplement of GM-CSF in MF-G2 (2ng/mL GM-CSF) and MF-G10 $(10 \mathrm{ng} / \mathrm{mL}$ GM-CSF) gently increased the percentage of class I oocytes compared to MF-G0 without $\mathrm{pFF}$ and GM-CSF, though these differences were nonsignificant. However, in the presence of pFF (MF$\mathrm{P} 2$ and MF-P10), GM-CSF reversed effects of pFF to lipid droplet distribution. Indeed, the percentage of oocytes with good lipid droplet re-arrangement significantly decreased $(60.6 \%$ in MF-P0, $31.7 \%$ in MF$\mathrm{P} 2$ and $16.7 \%$ in MF-P10) $(\mathrm{p}<0.05)($ Figure $7 \mathbf{A})$.

For oocytes from SFs, the supplement of $\mathrm{pFF}$ in the IVMM did not affect the lipid droplet rearrangement. The slight increase of class I oocytes was recorded in SF-G2 compared to SF-G0, but it was not significant. Similar to oocytes from medium follicles, in the presence of pFF, GM-CSF caused a strong reduction of oocytes with good lipid droplet distribution, especially at the high concentration of GMCSF $(10 \mathrm{ng} / \mathrm{mL})$. The percentage of class I oocytes was $12.5 \%$ in MF-P10, which is significantly lower than $33.33 \%$ in MF-P0 and $31.33 \%$ in MF-P2 ( $p<0.05)$ (Figure 7B).

\section{GM-CSF promoted the mitochondrial movement in oocytes from SFs and MFs}

The useful effects of pFF and GM-CSF on the mitochondrial distribution of oocytes from medium follicles were demonstrated in Figure 8. The supplement of GM-CSF significantly increased the percentage of M-type oocytes from $22.85 \%$ in MF-G0 to $46.88 \%$ in MF-G10 $(\mathrm{p}<0.05)$. The similar result was detected at the comparison between MF-P0 and MF-G0 (48.5\% in MF-P0) $(\mathrm{p}<0.05)$. We also recorded that the percentage of M-type oocytes in MF-G10 was not different to in MF-P0, which meant that $\mathrm{pFF}$ at $10 \%$ and
GM-CSF $10 \mathrm{ng} / \mathrm{ml}$ in standard IVMM would have the same effects on the mitochondrial distribution in medium follicles-derived oocytes.

In the presence of $\mathrm{pFF}$, the percentage of S-type oocytes strongly decreased from $42.42 \%$ in MF-P0 to $14.63 \%$ in MF-P2 $(\mathrm{p}<0.01)$; the percentage of M-type oocytes increased from $48.5 \%$ in MF-P0 to $70.7 \%$ in MF-P2, but this increase was not significant. Even though, when comparing MF-P2 to MF-G0, the percentage of S-type oocytes was much lower and the percentage of M-type oocytes was significantly higher $(\mathrm{p}<0.0001)(62.86 \%$ of S-type and $22.85 \%$ of M-type in MF-G0). However, when the GM-CSF concentration was up to $10 \mathrm{ng} / \mathrm{mL}$, the percentage of S- and Mtype oocytes in MF-P10 was similar to in MF-P0. In addition, when comparing the MF-P10 to MF-P2, the results showed a decrease $(\mathrm{p}<0.05)$ of M-type oocytes to $42.8 \%$ and an increase $(\mathrm{p}<0.05)$ of S-type oocytes up to $37.1 \%$ in MF-P10.

For assessment of SFs, the GM-CSF supplement significantly reduced the percentage of P-type oocytes from $26.5 \%$ in SF-G0 to $8.6 \%$ in SF-G2 (p<0.05). Similarly, this percentage in SF-P0 was $7.7 \%$, significantly lower than in SF-G0 $(\mathrm{p}<0.05)$ and there was no difference between SF-G2 and SF-P0. In the groups of pFF and GM-CSF supplement, the only significant difference was the percentage of S-type oocytes decreased from $56,4 \%$ in SF-P0 to $34,1 \%$ in SF-P10 $(\mathrm{p}<0.05)$ (Figure 9).

\section{GM-CSF showed positive effects on the cor- tical granule distribution of oocytes from SFs and MFs}

In medium follicle-derived COCs, after cultured, the percentage of three type oocytes were not significantly different between MF-G0 (without GM-CSF and pFF) vs. MF-P0 (only $10 \% \mathrm{pFF}$ ). This result suggested that $\mathrm{pFF}$ at $10 \%$ of IVMM could not affect the CG distribution. However, at the group of GM-CSF 2 $\mathrm{ng} / \mathrm{mL}$ (MF-G2), the percentage of C-type oocytes significantly reduced from $42.86 \%$ in MF-G0 to $20 \%$ $(\mathrm{p}<0.05)$. In addition, the concentration of $2 \mathrm{ng} / \mathrm{mL}$ GM-CSF (MF-G2) could enhance the percentage of M-type oocytes up to $65 \%$, significantly higher than $39.39 \%$ in MF-P0 ( $\mathrm{p}<0.05)$. Moreover, when GM-CSF concentration increased to $10 \mathrm{ng} / \mathrm{mL}$, the percentage of W-type oocytes in MF-G10 was 3.13\%, significantly lower compared to $21.21 \%$ of MF-P0 $(\mathrm{p}<0.05)$. These results showed that GM-CSF was better than $\mathrm{pFF}$ in the CG distribution (Figure 10).

In the combination of GM-CSF and pFF, at low concentration of GM-CSF (2ng/mL) (group MF-P2), the 



Figure 6: Effects of pFF and GM-CSF on the appearance of the first polar body in oocytes collected from (A) medium and (B) small follicles after IVM. ${ }^{* * *}$ significant difference with $p<0.05$ and $p<0.001$, respectively.
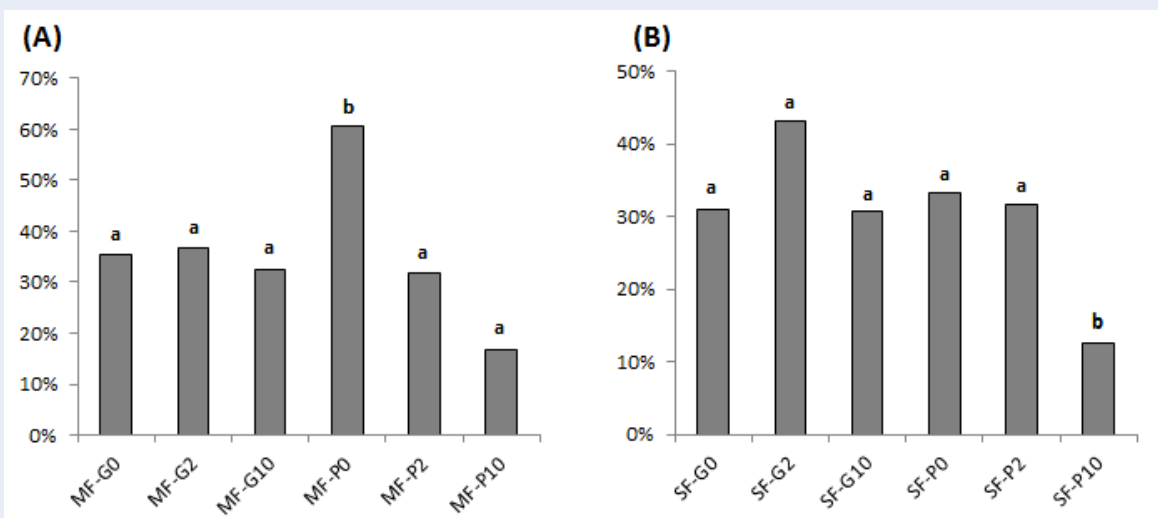

Figure 7: Effects of pFF and GM-CSF on the lipid droplet distribution in oocytes collected from (A) medium and (B) small follicles after IVM. Bars with different letters are significantly different $(p<0.05)$.

percentage of W-type oocytes significantly decreased compared to MF-P0 (without GM-CSF) $(\mathrm{p}<0.05)$ (4.88\% and $21.21 \%$, respectively). Besides, at higher concentration of GM-CSF $(10 \mathrm{ng} / \mathrm{mL})$, the percentage of C-type oocytes reduced in MF-P10 compared to MF-P0 and MF-P2 (17.14\% vs. $41.46 \%$ and $39.39 \%$ respectively for MF-P10, MF-P2, and MF$\mathrm{P} 0)(\mathrm{p}<0.05)$; and the M-type oocytes significantly increased from $39.39 \%$ at MF-P0 to $65.71 \%$ at MF-P10 $(\mathrm{p}<0.05)$. Initially, in combination with $\mathrm{pFF}$, GMCSF could stimulate the movement of cortical granules from the cytoplasm to oolema.

For the small follicle-derived COCs, the effects of GM-CSF and pFF were similar in the CG contribu- tion ( $\mathrm{p}>0.05)$. Reversely, in combination with $\mathrm{pFF}$, GM-CSF at $2 \mathrm{ng} / \mathrm{mL}$ strongly decreased the percentage of W-type oocytes compared to the IVMM supplemented with only GM-CSF or pFF $(9.76 \%, 33.33 \%$ and $29.41 \%$ for SF-P10, SF-P0, and SF-G0, respectively $)(\mathrm{p}<0.05)$. In addition, the percentage of $\mathrm{M}$ type oocytes significantly increased to $65.85 \%$ at SFP2 while compared to $25.64 \%$ at SF-P0 and $29.41 \%$ at SF-G0 ( $p<0.01)$. Thus, the GM-CSF and pFF combination stimulated the maturation of CGs (Figure 11). When GM-CSF increased to $10 \mathrm{ng} / \mathrm{mL}$ (SF-P10), the percentage of W-type oocytes reduced to $9.76 \%$, which is the same as SF-P2. However, the percentage of M-type oocytes significantly decreased to $36.59 \%$ at 




Figure 8: Effects of pFF and GM-CSF on the mitochondrial distribution in oocytes collected from medium follicles after IVM. */****** significant difference with $p<0.05, p<0.01$ and $p<0.0001$, respectively.

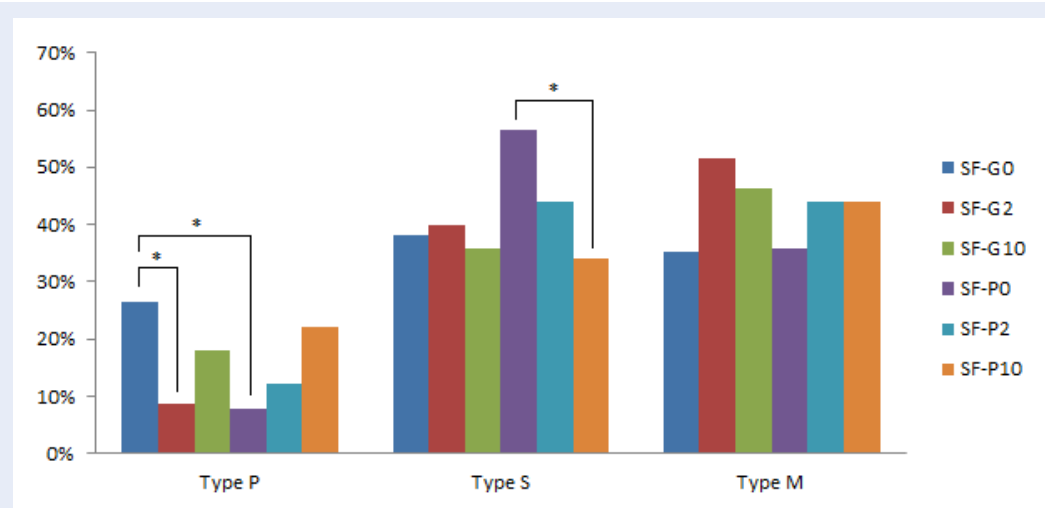

Figure 9: Effects of pFF and GM-CSF on the mitochondrial distribution in oocytes collected from small follicles after IVM. * significant difference with $p<0.05$

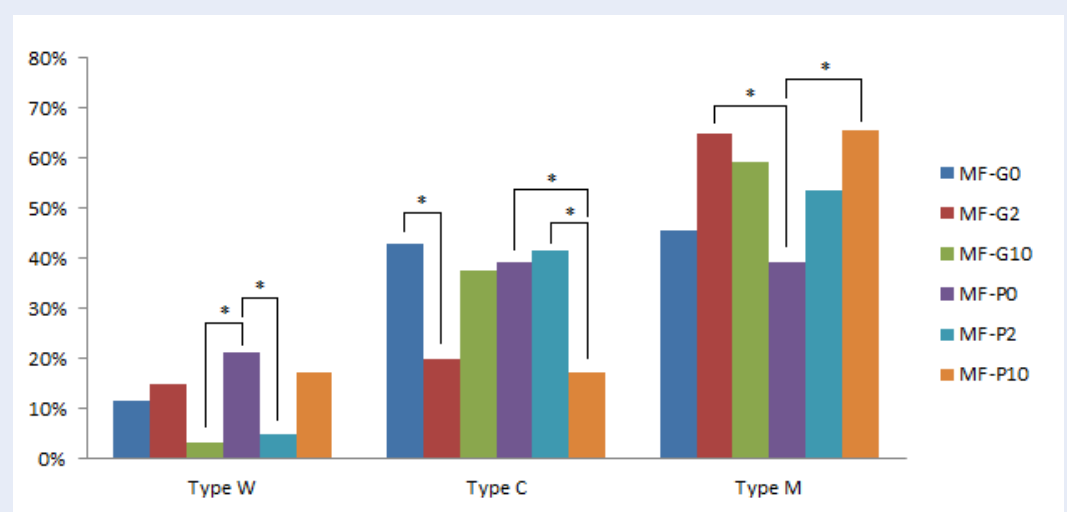

Figure 10: Effects of pFF and GM-CSF on the cortical granule distribution of in oocytes collected from medium follicles after IVM. * significant difference with $p<0.05$. 
SF-P10 in comparison with $65.85 \%$ at SF-P2 (p<0.01); and the percentage of C-type increased from $24.39 \%$ at SF-P2 to $53.66 \%$ at SF-P10 $(\mathrm{p}<0.01)$. Both became similar to which at SF-P0 and SF-G0. This observation suggested that the high concentration of GMCSF promoted the CG motility but inhibited the CG arrangement beneath the oolema.

\section{DISCUSSION}

In this study, we evaluated the maturation of porcine oocytes under GM-CSF treatment. In a few studies about the effects of GM-CSF on oocyte maturation, our study was the first one to evaluate the effect of GM-CSF in combination with pFF. Previously, the effect of GM-CSF was assessed only in a synthetic medium by using 10\% FBS in TCM 199 as the control $^{1}$.

In our experiment, GM-CSF has shown its effect on cumulus expansion. When comparing the average diameters of COCs at $20^{\text {th }}$ hour in the only-GMCSF supplemented group, a significant difference between MF-G10 and MF-G0 demonstrates that GMCSF stimulates the expansion of cumulus cell layers, which is consistent with the results in the previous study $^{32}$. Additionally, the COC average diameter of MF-G10 group was similar to MF-P0, and both were significantly higher than MF-G0 revealing that GMCSF had the same stimulation as pFF on cumulus cell dilatation. Moreover, the combination of $\mathrm{pFF}$ and GM-CSF induced strong expansion of the cumulus cells, and this effect was stronger than the addition of either pFF or GM-CSF.

According to Nagyova's study, cumulus expansion and hyaluronic acid synthesis in pigs did not depend on the secreted factor from oocytes ${ }^{33}$, which suggested that GM-CSF had a direct effect on cumulus cells. In addition, Peralta's research showed that GMCSF acted via the PI3K pathway ${ }^{32}$, and previous studies also showed that EGF receptor-dependent cumulus expansion mechanisms were via the PI3K, AKT, and MAPK $3 / 1^{34,35}$. Thus, it is possible that the GMCSF receptor may have a role in the cumulus expansion similar to the EGF receptor.

About the first polar body extrusion, our results showed that GM-CSF was harmful to the polar body extrusion rate in the group of oocytes from MFs and had no effect on the group of oocytes from SFs. However, in a previous study, GM-CSF was demonstrated not to affect the oocyte maturation rate when GMCSF levels were increased from 1 to $100 \mathrm{ng} / \mathrm{mL}^{32}$. These contradictory results may be due to Peralta assessed the impact of human GM-CSF on bovine oocytes, and our study evaluated the effect of porcine
GM-CSF on porcine oocyte. This explanation is supported by the fact that GM-CSF structure is species specific $^{36}$. Genetic suitability may be the reason why porcine GM-CSF has a strong impact on porcine oocytes.

In the nuclear maturation research, EGF was found that it functioned similarly to FSH activity under in vitro conditions, which could completely replace natural FSH in stimulating the polar body formation ${ }^{37}$. In addition, EGF-like factors also were shown to have similar effects, via the EGF receptor signaling pathways. However, FSH affected through a variety of signaling pathways, not just the EGF receptor ${ }^{38}$. Thus, the nuclear maturation in oocytes was regulated by multiple pathways, and the GM-CSF receptor might be one of them.

With the results obtained, GM-CSF showed its detrimental effect on the polar body formation, even in the presence of FSH, LH (in PMSG, hCG, pFF), and EGF. However, the mechanism behind this process still requires more research to clarify and identify the relevant signaling pathways in oocytes.

At the $20 \mathrm{ng} / \mathrm{mL}$ concentration (MF-P20), GM-CSF showed a strong decrease in the polar body extrusion rate compared to groups of $2 \mathrm{ng} / \mathrm{mL}$ and no supplementation. Therefore, we did not use the $20 \mathrm{ng} / \mathrm{mL}$ GM-CSF supplemented IVMM in the next experiments.

GM-CSF did not improve the lipid droplet distribution of oocytes. Additionally, GM-CSF reversed the beneficial effects of pFF when combined in IVMM. In the method article, Hiraga used a non-supplemented TFF medium, or TCM with serum, similar to the only pFF supplemented group in this study ${ }^{29}$. From 2013, there were no new studies have evaluated the distribution of lipid droplets after IVM. Therefore, the mechanism of lipid droplet migration has not been determined. It is hard to explain how pFF and GM-CSF affected the lipid droplet distribution. Our experiment was the first one to demonstrate the positive effects of pFF on the distribution of lipid droplets in oocytes after IVM.

In medium follicle-derived COCs, while single $\mathrm{pFF}$ or GM-CSF supplement enhanced the distribution of mitochondria throughout the ooplasm, the pFF and GM-CSF combination promoted the migration of mitochondria from the outer part to the whole oocyte. However, the high concentration of GM-CSF would negate these positive effects. On the other hand, GMCSF did not affect COCs from SFs. The slight decreases in the percentage of P-type oocytes meant GM-CSF might stimulate the re-arrangement of mitochondria at the early stage. There was not enough 


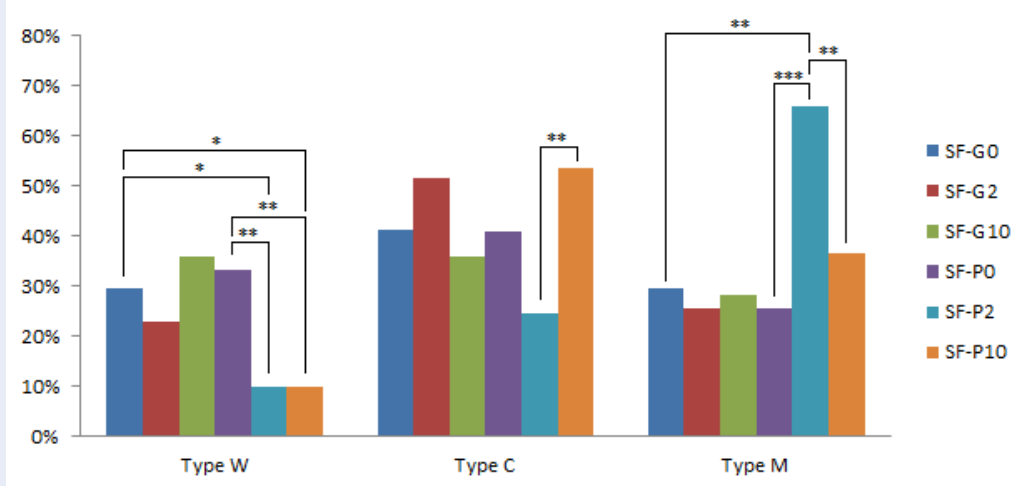

Figure 11: Effects of pFF and GM-CSF on the cortical granule distribution in oocytes collected from small follicles after IVM. ${ }^{* * *} /^{* * *}$ significant difference with $p<0.05, p<0.01$ and $p<0.001$, respectively.

proof for GM-CSF effects on the movements of mitochondria in the oocytes from SFs. In general, GMCSF had positive effects on the mitochondrial distribution of oocytes, which was stronger when combined with pFF but the combined effect was inactivated at high concentrations.

The mitochondrial distribution reflects the development of oocytes and the post-fertilization of embryos. Some studies showed the quality of oocytes and the rate of embryo formation decreased with the addition of harmful substances to the mitochondrial migration $^{39,40}$. However, the mechanisms and causes that affect the mitochondrial distribution in oocytes have not been fully investigated.

GM-CSF had a few beneficial effects on the CG distribution of oocytes from either MFs or SFs. Nevertheless, the combination of $\mathrm{pFF}$ and GM-CSF revealed these effects more clearly. When supplemented with $\mathrm{pFF}$ in IVM medium, GM-CSF could stimulate the movement of CGs from the cytoplasm to oolema and support the arrangement beneath the oocyte membrane.

Previous studies showed that the distribution of CGs was related to PI3K signaling pathways ${ }^{41}$. With the stimulation of GM-CSF, multiple signaling pathways were activated, including the PI3K pathway ${ }^{6}$. This may be the cause of the observed enhancement in CG arrangement. However, there are more experiments need to be done to find out the GM-CSF signaling pathways involved in the CG distribution in oocytes. According to a study by Revelli in 2009, there were 31 proteins found in $\mathrm{pFF}^{42}$. In addition, many other components have not been completely identified, and their function in the maturation of porcine oocytes is not fully understood. Therefore, the mechanism how GM-CSF and pFF acting on oocyte maturation must be identified before embryologists determine whether using GM-CSF in IVM technique.

\section{CONCLUSIONS}

GM-CSF did not affect the nuclear maturation and the lipid droplet localization. However, it improved the cumulus expansion in the in vitro maturation of porcine oocytes. Furthermore, it exhibited some benefits in the mitochondrial and cortical granule distribution, especially in combination with pFF in oocytes collected from 3-7 mm follicles. In conclusion, porcine GM-CSF had some positive effects on the porcine oocyte maturation.

\section{ABBREVIATIONS}

BSA: bovine serum albumin

CG: cortical granule

COC: cumulus-oocyte complex

CSF: colony-stimulating factor

EGF: epidermal growth factor

FF: follicular fluid

FSH: Follicle stimulating hormone

G-CSF: Granulocyte-colony stimulating factor

GM-CSF: Granulocyte Macrophage-colony stimulating factorh

CG: human chorionic gonadotropin

IL: interleukin

IU: international unit

IVM: in vitro maturation

IVMM: in vitro maturation medium

LH: Luteinizing hormone

JAK/STAT: Janus kinase/signal transducers and activators of transcription

MAPK: mitogen-activated protein kinase

MF: medium follicle 
PBS: Phosphate-buffered saline

PI3-K: phosphatidylinositol 3-kinase

PMSG: pregnant mare serum gonadotropin

PVA: polyvinyl alcohol

M-CSF: Macrophage colony stimulating factor

PCOS: Polycystic Ovary Syndrome

pFF: porcine follicular fluid

SF: small follicle

TLR: toll-like receptor

TNF: tumor necrosis factor

\section{COMPETING INTERESTS}

The authors report no conflicts of interest in this work.

\section{AUTHORS' CONTRIBUTIONS}

LTD: designed the experiments, conducted the experiments concerned to COCs from SFs, performed the mitochondrial and cortical granule distribution assays in COCs from MFs and wrote the manuscript. TTTL and CMH: isolated and cultured the COCs from MFs, performed the cumulus expansion, polar body extrusion and lipid droplet localization assays and wrote the manuscript. SNH: analyzed the data, discussed and revised the manuscript. All authors read and approved the final manuscript.

\section{ACKNOWLEDGMENTS}

The authors give thanks to B.Sc. Quy Xuan Nguyen for sample collection during methods testing; M.Sc. Oanh Thi-Kieu Nguyen and B.Sc. Nhat Chau Truong for assistance in statistical analysis and graph designing.

The study was financially supported by Laboratory of Stem Cell Research and Application, University of Science, Vietnam National University - Ho Chi Minh City, Vietnam.

\section{REFERENCES}

1. Deshmukh RS, Ostrup O, Ostrup E, Vejlsted M, Niemann $H_{\text {, }}$ Lucas-Hahn A. DNA methylation in porcine preimplantation embryos developed in vivo and produced by in vitro fertilization, parthenogenetic activation and somatic cell nuclear transfer. Epigenetics. 2011;6(2):177-87. Available from: 10. 4161/epi.6.2.13519.

2. Ito $M$, Iwata $H$, Kitagawa $M$, Kon $Y$, Kuwayama T, Monji $Y$. Effect of follicular fluid collected from various diameter follicles on the progression of nuclear maturation and developmental competence of pig oocytes. Anim Reprod Sci. 2008;106(34):421-30. Available from: 10.1016/j.anireprosci.2007.06.003

3. Oberlender G, Murgas LD, Zangeronimo MG, da Silva AC, Menezes TA, Pontelo TP, et al. Role of insulin-like growth factor-I and follicular fluid from ovarian follicles with different diameters on porcine oocyte maturation and fertilization in vitro. Theriogenology. 2013;80(4):319-27. Available from: 10.1016/j.theriogenology.2013.04.018.
4. Rahmati M, Petitbarat M, Dubanchet S, Bensussan A, Chaouat G, Ledee N. Colony Stimulating Factors 1, 2, 3 and early pregnancy steps: from bench to bedside. J Reprod Immunol. 2015;109:1-6. Available from: 10.1016/j.jri.2015.01.005.

5. Sirotkin AV, Dukesová J, Makarevich AV, Kubek A, Bulla J. Evidence that growth factors IGF-I, IGF-II and EGF can stimulate nuclear maturation of porcine oocytes via intracellular protein kinase A. Reprod Nutr Dev. 2000;40(6):559-69. Available from: 10.1051/rnd:2000137.

6. Martinez-Moczygemba M, Huston DP. Biology of common beta receptor-signaling cytokines: IL-3, IL-5, and GM-CSF. J Allergy Clin Immunol. 2003;112(4):653-65. Available from: 10.1016/j.jaci.2003.08.015.

7. Hayashida K, Kitamura T, Gorman DM, Arai K, Yokota T, Miyajima A. Molecular cloning of a second subunit of the receptor for human granulocyte-macrophage colony-stimulating factor (GM-CSF): reconstitution of a high-affinity GM-CSF receptor. Proc Natl Acad Sci USA. 1990;87(24):9655-9. Available from: 10.1073/pnas.87.24.9655.

8. Robertson SA. GM-CSF regulation of embryo development and pregnancy. Cytokine Growth Factor Rev. 2007;18(34):287-98. Available from: 10.1016/j.cytogfr.2007.04.008.

9. Burgess AW, Camakaris J, Metcalf D. Purification and properties of colony-stimulating factor from mouse lungconditioned medium. J Biol Chem. 1977;252(6):1998-2003.

10. Metcalf $D$. The molecular biology and functions of the granulocyte-macrophage colony-stimulating factors. Blood. 1986;67(2):257-67.

11. Takahashi M, Nikkuni K, Moriyama Y, Shibata A. GM CSF-mediated impairment of liver to synthesize albumin, cholinesterase, and cholesterol. Am J Hematol. 1991;36(3):213-4. Available from: 10.1002/ajh.2830360312.

12. Frank J, Engler-Blum G, Rodemann HP, Müller GA. Human renal tubular cells as a cytokine source: PDGF-B, GM-CSF and IL-6 mRNA expression in vitro. Exp Nephrol. 1993;1(1):26-35.

13. Nishihara $T$, Ochi M, Sugimoto $K$, Takahashi $H$, Yano H, Kumon $\mathrm{Y}$, et al. Subcutaneous injection containing IL-3 and GM-CSF ameliorates stab wound-induced brain injury in rats. Exp Neurol. 2011;229(2):507-16. Available from: 10.1016/j.expneurol 2011.04.006.

14. Fleetwood AJ, Cook AD, Hamilton JA. Functions of granulocyte-macrophage colony-stimulating factor. Crit Rev Immunol. 2005;25(5):405-28. Available from: 10.1615/ CritRevImmunol.v25.i5.50.

15. Sallerfors B. Endogenous production and peripheral blood levels of granulocyte-macrophage (GM-) and granulocyte (G colony-stimulating factors. Leuk Lymphoma. 1994;13(34):235-47. Available from: 10.3109/10428199409056287.

16. Hamilton JA. Colony-stimulating factors in inflammation and autoimmunity. Nat Rev Immunol. 2008;8(7):533-44. Available from: $10.1038 /$ nri2356.

17. Shannon MF, Himes SR, Coles LS. GM-CSF and IL-2 share common control mechanisms in response to costimulatory signals in T cells. J Leukoc Biol. 1995;57(5):767-73. Available from: 10.1002/jlb.57.5.767.

18. van Nieuwenhuijze A, Koenders M, Roeleveld D, Sleeman MA van den Berg W, Wicks IP. GM-CSF as a therapeutic target in inflammatory diseases. Mol Immunol. 2013;56(4):675-82. Available from: 10.1016/j.molimm.2013.05.002

19. Conti L, Gessani S. GM-CSF in the generation of dendritic cells from human blood monocyte precursors: recent advances. Immunobiology. 2008;213(9-10):859-70. Available from: 10 . 1016/j.imbio.2008.07.017.

20. Barreda DR, Hanington PC, Belosevic M. Regulation of myeloid development and function by colony stimulating factors. Dev Comp Immunol. 2004;28(5):509-54. Available from: 10.1016/ j.dci.2003.09.010.

21. Robertson SA, Sjöblom C, Jasper MJ, Norman RJ, Seamark RF. Granulocyte-macrophage colony-stimulating factor promotes glucose transport and blastomere viability in murine preimplantation embryos. Biol Reprod. 2001;64(4):1206-15. Available from: 10.1095/biolreprod64.4.1206. 
22. Peralta OA, Bucher D, Angulo C, Castro MA, Ratto MH, Concha I. Tissue localization of GM-CSF receptor in bovine ovarian follicles and its role on glucose uptake by mural granulosa cells. Anim Reprod Sci. 2016;170:157-69. Available from: 10.1016/j.anireprosci.2016.04.014.

23. Sjöblom C, Wikland M, Robertson SA. Granulocytemacrophage colony-stimulating factor (GM-CSF) acts independently of the beta common subunit of the GM-CSF receptor to prevent inner cell mass apoptosis in human embryos. Biol Reprod. 2002;67(6):1817-23. Available from: 10.1095/ biolreprod.101.001503.

24. Calhoun DA, Jr WHD, Du Y, Dame JB, Li Y, Christensen RD. Distribution of granulocyte colony-stimulating factor (G-CSF) and G-CSF-receptor mRNA and protein in the human fetus. Pediatr Res. 1999;46(3):333-8. Available from: 10.1203/ 00006450-199909000-00015.

25. Hammadeh ME, Fischer-Hammadeh C, Georg T, Rosenbaum P, Schmidt W. Comparison between cytokine concentration in follicular fluid of poor and high responder patients and their influence of ICSI-outcome. Am J Reprod Immunol. 2003;50(2):131-6. Available from: 10.1034/j.1600-0897.2003. 00062.x.

26. Li R, Murphy CN, Spate L, Wax D, Isom C, Rieke A, et al. Production of piglets after cryopreservation of embryos using a centrifugation-based method for delipation without micromanipulation. Biol Reprod. 2009;80(3):563-71. Available from: 10.1095/biolreprod.108.073387.

27. Gil MA, Maside C, Cuello C, Parrilla I, Vazquez JM, Roca J, et al. Effects of Hoechst 33342 staining and ultraviolet irradiation on mitochondrial distribution and DNA copy number in porcine oocytes and preimplantation embryos. Mol Reprod Dev. 2012;79(9):651-63. Available from: 10.1002/mrd.22071.

28. Lin T, Diao YF, Kang JW, Lee JE, Kim DK, Jin DI. Chromosomes in the porcine first polar body possess competence of second meiotic division within enucleated MII stage oocytes. PLoS One. 2013;8(12):e82766. Available from: 10.1371/journal. pone.0082766.

29. Hiraga K, Hoshino Y, Tanemura K, Sato E. Selection of in vitromatured porcine oocytes based on localization patterns of lipid droplets to evaluate developmental competence. J Reprod Dev. 2013;59(4):405-8. Available from: 10.1262/jrd.2012126.

30. Pawlak P, Chabowska A, Malyszka N, Lechniak D. Mitochondria and mitochondrial DNA in porcine oocytes and cumulus cells-a search for developmental competence marker. Mitochondrion. 2016;27:48-55.

31. Lin T, Diao YF, Choi HS, Oqani RK, Kang JW, Lee JE, et al. Procedure used for denuding pig oocytes influences oocyte damage, and development of in vitro and nuclear transfer embryos. Animal reproduction science. 2015;152:65-76.

32. Peralta OA, Bucher $D$, Fernandez $A$, Berland $M$, Strobel $P$,
Ramirez A. Granulocyte-macrophage colony stimulating factor (GM-CSF) enhances cumulus cell expansion in bovine oocytes. Reprod Biol Endocrinol. 2013;11(1):55. Available from: 10.1186/1477-7827-11-55.

33. Nagyová E, Procházka R, Vanderhyden BC. Oocytectomy does not influence synthesis of hyaluronic acid by pig $\mathrm{Cu}-$ mulus cells: retention of hyaluronic acid after insulin-like growth factor-I treatment in serum-free medium. Biol Reprod. 1999;61(3):569-74. Available from: 10.1095/biolreprod61.3. 569.

34. Conti M, Hsieh M, Park JY, Su YQ. Role of the epiderma growth factor network in ovarian follicles. Mol Endocrinol. 2006;20(4):715-23. Available from: 10.1210/me.2005-0185.

35. Nemcová L, Nagyová E, Petlach $M$, Tománek M, Procházka R. Molecular mechanisms of insulin-like growth factor 1 promoted synthesis and retention of hyaluronic acid in porcine oocyte-cumulus complexes. Biol Reprod. 2007;76(6):1016-24. Available from: 10.1095/biolreprod.106.057927.

36. Hill AD, Naama HA, Calvano SE, Daly JM. The effect of granulocyte-macrophage colony-stimulating factor on myeloid cells and its clinical applications. J Leukoc Biol. 1995;58(6):634-42. Available from: 10.1002/jlb.58.6.634.

37. Uhm SJ, Gupta MK, Yang JH, Chung HJ, Min TS, Lee HT. Epidermal growth factor can be used in lieu of follicle-stimulating hormone for nuclear maturation of porcine oocytes in vitro. Theriogenology. 2010;73(8):1024-36. Available from: 10 . 1016/j.theriogenology.2009.11.029.

38. Mito T, Yoshioka K, Noguchi M, Yamashita S, Hoshi H. Recombinant human follicle-stimulating hormone and transforming growth factor-alpha enhance in vitro maturation of porcine oocytes. Mol Reprod Dev. 2013;80(7):549-60. Available from: $10.1002 / \mathrm{mrd} .22190$

39. Magata F, Shimizu T. Effect of lipopolysaccharide on developmental competence of oocytes. Reprod Toxicol. 2017;71:1-7. Available from: 10.1016/j.reprotox.2017.04.001.

40. Stojkovic M, Machado SA, Stojkovic P, Zakhartchenko V, Hutzler $\mathrm{P}$, Gonçalves $\mathrm{PB}$, et al. Mitochondrial distribution and adenosine triphosphate content of bovine oocytes before and after in vitro maturation: correlation with morphological criteria and developmental capacity after in vitro fertilization and culture. Biol Reprod. 2001;64(3):904-9. Available from: 10.1095/biolreprod64.3.904.

41. Tumova L, Romar R, Petr J, Sedmikova M. The effect of protein kinase $C$ activator and nitric oxide donor on oocyte activation and cortical granule exocytosis in porcine eggs. Animal : an international journal of animal bioscience. 2013;7(2):279-286. Available from: 10.1017/S1751731112001127.

42. Revelli A, Piane LD, Casano S, Molinari E, Massobrio M, Rinaudo P. Follicular fluid content and oocyte quality: from single biochemical markers to metabolomics. Reprod Biol Endocrinol. 2009;7(1):40. Available from: 10.1186/1477-7827-7-40. 